Saudi Journal of Medicine

Abbreviated Key Title: Saudi J Med ISSN 2518-3389 (Print) |ISSN 2518-3397 (Online) Scholars Middle East Publishers, Dubai, United Arab Emirates Journal homepage: https://saudijournals.com/sjm

Case Report

\title{
Laryngeal Location of Amylosis: A Case Report
}

\section{Khaoula Karim $^{1 *}$, Razika Bencheikh ${ }^{2}$, Nourredine Mahiou ${ }^{1}$, Nadia $\mathrm{Cherradi}^{3}$, Mohammed anas Benbouzid ${ }^{2}$, Leila} Essakalli $^{2}$

${ }^{1}$ Resident Physician in Otorhinolaryngology, Department of Otorhinolaryngology, Head and Neck Surgery, Ibn Sina University Hospital, Faculty of Medicine, Mohammed V University, Rabat, Morocco

${ }^{2}$ Professor of Otorhinolaryngology, Department of Otorhinolaryngology, Head and Neck Surgery, Ibn Sina University Hospital, Faculty of Medicine,Mohammed V University, Rabat, Morocco

${ }^{3}$ Professor of Pathological Anatomy, Department of pathological anatomy, Ibn Sina University Hospital, Faculty of Medicine, Mohammed V University, Rabat, Morocco

DOI: $10.36348 / \mathrm{sjm} .2020 . \mathrm{v} 05 \mathrm{i} 03.008$

| Received: 10.02.2020 | Accepted: 18.02.2020 | Published: 21.03.2020

*Corresponding author: Khaoula Karim

\section{Abstract}

Amyloidosis includes different forms of organic or systemic damage; it is characterized by deposits fibrillar in the connective tissue. At the ENT level, isolated involvement of the larynx is the most observed. However, isolated laryngeal involvement is rare. A search for forms multifocal or systemic by means of complementary examinations is therefore recommended. Preferential treatment of laryngeal form is endoscopic surgery with preservation functional.

Key words: Dysphony, dyspnea, nodules, vocal cords.

Copyright @ 2020: This is an open-access article distributed under the terms of the Creative Commons Attribution license which permits unrestricted use, distribution, and reproduction in any medium for non-commercial use (NonCommercial, or CC-BY-NC) provided the original author and source are credited.

\section{INTRODUCTION}

Amyloidosis is characterized by the deposition of amyloid fibrillar protein in various organs of the body. The localized form is rare, characterized by the absence of systemic involvement. One of the rarest sites where amyloidosis occurs is the larynx.

\section{CASE REPORT}

Our case is about a woman of 50 years, without notable antecedent, who presents since 08 months a permanent chronic dysphonia, associated with a dyspnea inspiratory progressive without other associated sign, admitted to emergency in a table of severe dyspnea having need the tracheostomy.

The chest X-ray was normal. The laryngeal CT scan was performed demonstrating a regular laryngeal glottic and subglottic stenosis enhanced after injection of contrast product, extending over approximately 8 $\mathrm{mm}$ below and considerably reducing the glottic lumen (Figure 1, 2).

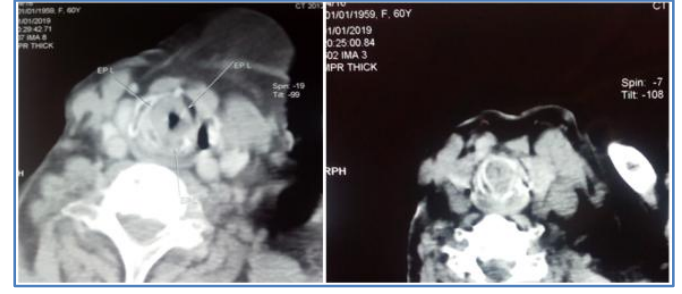

Fig-1, 2: Laryngeal CT scan demonstrating glottic and subglottic stenosis reducing the laryngeal lumen

Direct laryngoscopy showed whitish nodular lesions taking the two vocal cords obstructing the laryngeal lumen; anatomopathological examination of the biopsies carried out revealed a laryngeal amyloidosis. Figure [3-5].

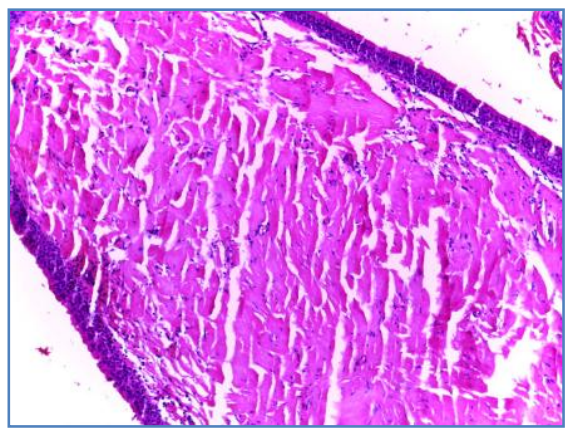

Fig-3: Microscopic image of the laryngeal biopsy showing a respiratory type mucosa with an eosinophilic deposit located in the chorion 


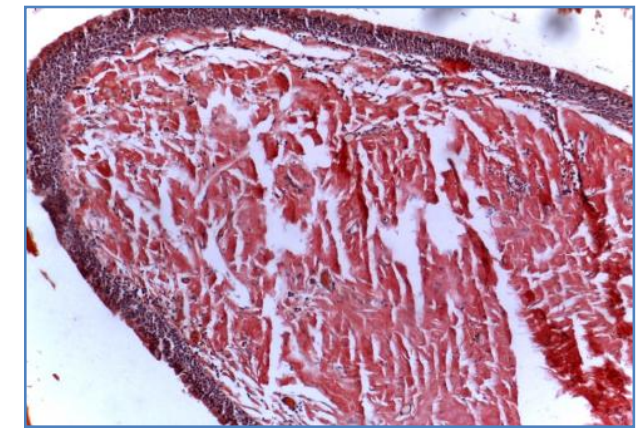

Fig-4: Eosinophilic deposit is colored in brick red by Congo red

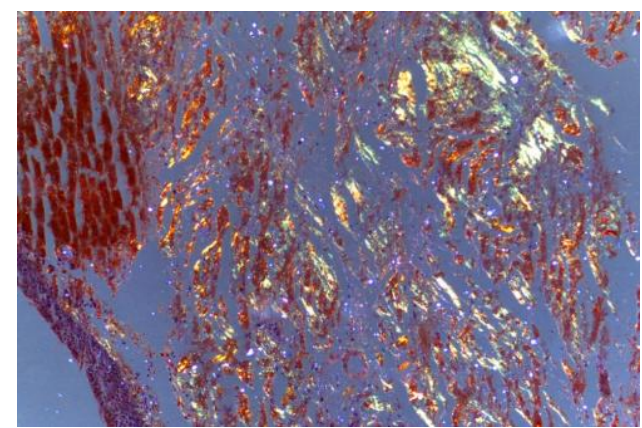

Fig-5: Microscopic image showing that the Congo red seen in polarized light shows a yellow-green birefringence of the amyloid deposit

The patient was referred to the internal medicine department, where a complementary assessment was made (renal assessment, renal ultrasound, ECG, chest $\mathrm{x}$-ray) concluding with localized laryngeal amyloidosis.

\section{DISCUSSION}

Amyloidosis is derived from the Greek words amylon, which means "starch", and "eidos", which means "resemblance". Called amylose by Virchow in 1854 because of its dye properties after coloring with iodine and sulfuric acid [1].

Amyloid deposits are made up of low molecular weight subunits derived from various soluble proteins, circulating in the blood plasma and having had conformational changes. They are the cause of several clinical manifestations depending on their type and location.

Amyloidosis can be hereditary or acquired, localized or disseminated, asymptomatic or, on the contrary, a formidable prognosis, it is a heterogeneous group of diseases linked to an extracellular deposit of proteins capable of adopting an abnormal fibrillar conformation. Localized forms are rare and represent less than $10 \%$ of amyloidosis [2, 3].

There are several classifications; a distinction was made between primary amyloidosis (AL) and secondary amyloidosis (AA).
The AL is due to protein deposits derived from light chain (L) fragments of immunoglobulins (Ig). AA is a potential complication of chronic or recurrent inflammation, causing the production of amyloid (A) in serum, which sediment in fibrillar form; AA corresponds to $5 \%$ of cases of amyloidosis [4]. Most cases of amyloidosis of the cervico-facial region are the localized forms of the AL type.

The submandibular gland is the most frequent ENT site for systemic AL (31.9\%), followed by the tongue (macroglossia, 23\%) [11, 12], thus deposits in the orbit, sinuses, pharynx and larynx $[5,6]$.

Amyloidosis accounts for $0.2-1.2 \%$ of all benign laryngeal tumors [7], the extent has been described on all levels. Some authors have stated that the most common location is the real vocal cord [8].

During the clinical examination, the mucosa is generally intact; lesions are yellowish, pinkish nodular submucosa (4). Man is most often affected (sex ratio M: $\mathrm{F}=2-3$ ), manifesting between the ages of 40 and 70 (9). The revealing signs are dysphonia, dyspnea, stridor (obstruction of the airways), hemoptysis, cough, sleep apnea syndrome, odynodysphagia [7].

The etiology remains unknown; in $85 \%$ of cases, it is characterized by deposits of light chains of $\operatorname{Ig} \lambda(60 \%)$ and $\kappa(25 \%)$ representing the localized form of AL amyloidosis.

\section{Three plausible hypotheses have been put forward}

- It is an immune disorder generating a precursor Ig producing amyloid by polymerization [10].

- Clones of plasma cells producing light chains of Ig, degraded to amyloid by enzymes of the connective tissue [11].

- The deposits are the result of the degradation / destruction of benign extramedullary plasmocytomas, or are the result of lymphoproliferative disorders associated with MALT (mucosa associated lymphoid tissue) [12].

In our case, the disease was revealed by permanent dysphonia with progressive inspiratory dyspnea. The delay between the first clinical signs and the diagnosis is often long, in our case it was 8 months.

At direct laryngoscopy the nodular aspect found in $44 \%$ in front, in front of the diffuse infiltrating aspect extended to the glottic and supra-glottic stage, a neoplastic etiology can be wrongly mentioned.

The diagnosis is based on anatomopathological examination where the amyloid deposits appear birefringent in polarized light with Congo red coloring [1]. 
Once the diagnosis has been established, the classification of amyloidosis according to the protein nature of the precursor must be clarified by an immunohistochemical examination, where fragments are frozen using different antibodies, light antichains, anti-SAA and antitransthyretin. At least 21 different proteins have been recognized to date as the causative agent of amyloidosis [13].

The search for a systemic extension must be done before retaining the diagnosis of a localized form. By looking for kidney, heart or skin damage. Biopsies of the rectal, cutaneous accessory salivary glands are sometimes necessary.

The treatment of localized forms essentially involves local surgical procedures, laser excision by microinstruments [14].

However, surgical procedures rarely achieve complete destruction of amyloid deposits, especially for subglottic locations. The $\mathrm{CO} 2$ laser has been used by Wooks and McIlwain and Talbot with good results [12, $14,15]$.

Other therapeutic means such as radiotherapy, chemotherapy and corticosteroid therapy remain much discussed. The risk of recurrence is low after a complete excision [16].

\section{CONCLUSION}

Localized laryngeal amyloidosis is uncommon; Dysphonia is the most common symptom. Direct laryngoscopy allows an extension assessment local and a biopsy which confirms the diagnosis.

An extension assessment must be made in search of a systemic form. The treatment includes local surgical procedures to perform a complete excision of the amyloid deposits in order to reduce the risk of recurrences.

\section{REFERENCES}

1. Ayadhi, oueslati, Z., Ben, azzouna, H., Toumi, S. (2001). Amylose laryngée à propos d'un CAS. J. Tun. ORL, 7 36-39.

2. Passerotti, G. H., Caniello, M., Hachiya, A., Santoro, P. P., Imamura, R., \& Tsuji, D. H. (2008). Multiple-sited amyloidosis in the upper aerodigestive tract: case report and literature review. Brazilian journal of otorhinolaryngology, 74(3), 462-466.

3. Alaani, A., Warfield, A. T., \& Pracy, J. P. (2004). Management of laryngeal amyloidosis. The journal of laryngology \& otology, 118(4), 279-283.
4. Penner, C. R., \& Müller, S. (2006). Head and neck amyloidosis: a clinicopathologic study of 15 cases. Oral oncology, 42(4), 421-429.

5. Prokaeva, T., Spencer, B., Kaut, M., Ozonoff, A., Doros, G., Connors, L. H., ... \& Seldin, D. C. (2007). Soft tissue, joint, and bone manifestations of AL amyloidosis: clinical presentation, molecular features, and survival. Arthritis \& Rheumatism: Official Journal of the American College of Rheumatology, 56(11), 3858-3868.

6. Wierzbicka, M., Budzyński, D., Piwowarczyk, K., Bartochowska, A., Marszałek, A., \& Szyfter, W. (2012). How to deal with laryngeal amyloidosis? Experience based on 16 cases. Amyloid, 19(4), 177 181.

7. Bartels, H., Dikkers, F. G., Lokhorst, H. M., Van Der Wal, J. E., \& Hazenberg, B. P. (2004). Laryngeal amyloidosis: localized versus systemic disease and update on diagnosis and therapy. Annals of Otology, Rhinology \& Laryngology, 113(9), 741-748.

8. Wang, Q., Chen, H., \& Wang, S. (2014). Laryngotracheobronchial amyloidosis: a case report and review of literature. International journal of clinical and experimental pathology, 7(10), 7088.

9. Deviprasad, D., Pujary, K., Balakrishnan, R., \& Nayak, D. R. (2013). KTP laser in laryngeal amyloidosis: five cases with review of literature. Indian Journal of Otolaryngology and Head \& Neck Surgery, 65(1), 36-41.

10. Gean-Marton, A. D., Kirsch, C. F., Vezina, L. G., \& Weber, A. L. (1991). Focal amyloidosis of the head and neck: evaluation with CT and MR imaging. Radiology, 181(2), 521-525.

11. Troxler, R. F., Kane, K., Berg, A. M., Grillone, G., Cohen, A. S., Kasznica, J., \& Skinner, M. (1993). Localized amyloidosis of the larynx: evidence for light chain composition. Annals of Otology, Rhinology \& Laryngology, 102(11), 884-889.

12. Talbot, A.R.(1990). Laryngeal amyloidosis. $J$ Laryngol Otol, 104:147-9.

13. Glenner, G.G. (1980). Amyloid deposits and amyloidosis. N Engl J Med. 302:1333-43.

14. McIlwain, J.C., Shepperd, H.W.H.(1986). Laser treatment of primary amyloidosis of the larynx. $J$ Laryngol Otol, 100:1079-1080

15. Woo, K. S., Van, C. H., \& Waldron, J. (1990). Laser resection of localized subglottic amyloidosis. The Journal of otolaryngology, 19(5), 337-338.

16. Villagomez, V., Santos, F., Santos, R., Trevino, J. L., \& Cantu, E. (2004). Amyloidosis: Uncommon cause of dysphonia. Otolaryngology--Head and Neck Surgery, 131(2), P275-P276. 